\title{
AÇĀO DA HIDROXOCOBALAMINA NA INTOXICAÇÃO AGLDA DO COELHO PELO HOLOCALIX BALANSAE, MICH.
}

\section{RFMVA-11}

SouzA, J. A. et al. - Açio da hidroxocobalamina na intoxicaça aguda do coelho pelo holocalix balansae, Mich.. Rev. Far. Med. vet. Zootc. Univ. S. Paulo, 8:15964,1972 .

RESUMO - Os autores provocaram a intoricagdo experimental em 15 coethos pelo extrato aquoso do Holocalix balansae, Mich., através da administração endovenosa (veia marginal da orelha). Os animais foram distribuidos em 3 grupos, constituidos por 5 animais cada um. O Grupo A considerado testemunho, não recebeu nenhuma proteção de hidroxocobalamina. O grupo $B$, receber $10 \mathrm{mg} / \mathrm{Kg}$ de hidroxocobalamina endovenosamente, 5 minutos ap6s $a$ injeccão endovenosa do cxtrato aquoso de Holocalix balansae, Mich. $(\$, 0 \mathrm{~g} / \mathrm{Kg})$. Finalments, $O$ grupo $C$ recebeu previamente hidroxocobrlamina $(10 \mathrm{mg} / \mathrm{Kg})$ endovenosamente, $5 \mathrm{mi}$ nutos antes da administração endovenosa do extrato aquoso de Holocalix balansae, Mich. $(3,0 \mathrm{~g} / \mathrm{Kg})$. O extrato aquoso de Holocalix balansae, Mich. foi preparado de conformidade com a orientação imprimida por SOUZA (1967). A presença de cianeto nas amostras foi confirmada através da determinação qualitativa de FEIGL (1954).

Constataram morte de todos os animais do grupo A, 10 minutos apbs a injeção do extrato aquoso de Holocalix balansae, Mich., precedida por acentuadas alteraçōes da freqüéncia respiratoria. Năo foi constatada nerhuma morte entre os animais pertencentes aos grupos $B$ e C. Alteraçōes da freqüéncia respiratbria foram observadas entre os animais do grupo $B$, nos 5 minutos que precederam as injecoses endovenosas de hidroxocobalamina e após as injeçoses de extrato

\author{
José Alves SOUZA *
Euclydes O. MARTINS ** \\ José Alves SOUZA *
Euclydes O. MARTINS * \\ Luiz ZEZZA NETO **
}

LuIz ZEZZA NETO

aquoso de Holocalix balansae, Mich. Os animais do grupo $C$ ñ̃o registraram quaisquer alteraçes $\mathrm{cm}$ seu comportamento vigirudo.

Finalmente, concluem ser a hidrovocobalamian a substíncia idcal na profilaxia $e$ tratamento das intoxicacóes cianidricas pelo Holocalix balansae, Mich., extcnsiva as demais plantas cianogenéticas.

UNITERMos: Hidroxocobralamina *; Intoxicaçāo*; Holocalix balansac *; Coelho*.

\section{N T RO DU C A O}

A leguminosa Holocalix balansae, Mich., vulgarmente conhecida como "alecrim das matas", "alecrim dos campos". "alecrim de Campinas" LUCAS? (1941) e ROCHA \& SILVA \& (1940), planta palatável, altamente tóxico, possui larga distribuiçăo geográfica no Brasil, Argentina e Paraguai BURKART ${ }^{1}$ (1952). Segundo ROCHA \& SILVA \& (1940), é o agente etiológico da chamada "peste das queimadas" que vitima bovinos criados em zonas de derrubadas. No estudo da toxidinámica desta planta, considera-se até o momento, pelo menos dols agentes etiológicos: o cianeto ${ }^{\circ}$ de ação rápida e fulminante e o pinitol 11, de açăo mais lenta, provocando alterações hepáticas, capazes de responder pelo aparecimento do fenómeno da fotossensibilizaçăo em bovinos que acom-

- Pror. Assistente, Conselho Naclonal de Pesquisas.

- Prof. Catedrático. Departamento de Patologia e Clínica Médicas da Faculdade de Medlcina Veterinária e Zootecnia da USP.

- Prof. Titular. Faculdade de Ciencias Medicas e Blológicas de Botucatu. 
SOUZA, J. A. et al. - Açao da hldroxocobalamina na intoxicacăo aguda do coelho pelo holocalix balansae, Mich. Rev. Fac, Med. vet. Zoolec. Univ. S. Paulo, 8:159-64, 1972.

panha o quadro clínico da intoxicação pelo Holocalix balansue, Mich.

A fitotoxicologia apresenta-se de impor táncia económica relevante, pois é grande o númro de plantas tóxicas que se desenvolvem de permeio ás pastagens naturais. Algumas dessas plantas apresentam o máximo de sua toxicidade no período de floração 8 , cnquanto outras atingem niveis maiores no periodo correspondente ao aparecimento de novos brotos 5 . Deve-se destacar o fato que em ambos os casos, há uma coincidência do ciclo vegetativo da planta, com o perlodo de sua máxima toxicidade e com a escassez de gramíneas nos campos naturais, onde os animais normalmente obtém sua fontc principal de alimentos.

Como planta cianogenética, a intoxicaçăo aguia pelo Holocalix balansac, Mich., implica $\mathrm{em}$ pronto atendimento aos animais acometioios por esta intoxicação.

A hidroxocobalamina tem sido cstudada no tratamento da intoxicação pelo cianeto 3,10 . No presente trabalho procuramos avaliar cm coelhos, o comportamento da hidroxocobalamina na intoxicaçăo experimen(a) aguda pelo Holocalix balansac, Mich.

\section{MATERTAL E METODOS}

Extrato aquoso de Holocalix balansae, Mich., foi obtido segundo método utilizado por SOUZA 11 (1967). A presença de claneto nas amostras injetadas nos animais em experiéncia, fol confirmada através do teste qualitativo de FEIGL + (1954). Para administraçăo aos animais submetidos à experimentaçăo, o extrato vegetal foi veiculado em soluçáo fisiológica e injetado através da veia marginai da orelha. Empregou-se a soluçāo de hidrovocobalamina de procedéncia comercial denominada "Droxofor".

Utilizaram-se 15 coelhos adultos, de ambos os sexos, raça Gigante de Flanders, em boas condiçరes de saúde. Os animais foram distribuldos ao acaso em grupos, denominados respectivamente $A, B$ e $C$. Cada grupo representado por 5 animais. A posologia, via de administraçáo e sequéncia da experiên- cía, consta na tabela I. Todos os animias foram observados por periodo de tempo de 30 minutos após a administraçūo do extrato aquoso de Holocalix balansue, Mich., por via venosa.

\section{RESULTADOS}

GRUPO A - Todos os animais destc grupo experimental, morreram no final de 10 minutos aposs as injeçōes endovenosas do extrato aquoso de Holocalix bulansae, Mich. na dose de $3,0 \mathrm{~g} / \mathrm{Kg}$. Fm todos os animais a morte foi precedida por nitidas alteraçōes da frequéncia respiratória.

GRUPO B - A hidroxocobalamina na dose de $10 \mathrm{mg} / \mathrm{Kg}$, injetada na veia marginal da orelha 5 minutos após a administraçāo venosa do extrato aquoso de Holoculix balansae, Mich., permitiu a sobrevivência de todos os animais integrantes deste grupo experimental. Constatou-se $\mathrm{cm}$ todos os animais deste grupo, evidentes alteraçōes da freqüéncia respiratória, restabelecida ao normal, cm média, 2,5 minutos após a injeçāo da Hidroxocobalamina $\mathrm{cm}$ altas doses (10 $\mathrm{mg} / \mathrm{Kg}$ )

GRUPO C - A hidroxocobalamina (10 $\mathrm{mg} / \mathrm{Kg}$ ) administrada endovenosamente 5 minutos antes da injeção, na veia marginal da orelha, do extrato aquoso de Holocalix balansae, Mich., na dose de $3,0 \mathrm{~g} / \mathrm{Kg}$. impediu o aparecimento de alteraçōes da freqüéncia respiratória, tabclas $I \in$ II.

Durante o periodo experimental, năo se observou qualquer alteraçāo respiratória digna de registro. Igualmente, nāo foi re. gistrada nenhuma morte entre os animais pertencentes a estc grupo de estudo experimental.

Os resultados alcançados por esta experimentação, envolvendo os 3 grupos animais de estudo, estão condensados na tabela II.

\section{I S C U S A O}

A hidroxocobalamina é um princlpio vitaminico $\mathrm{B}_{12}$ natural, designado como vitamina $B_{21}$ b. E obtida pela exposiçăo da vl- 
SouzA, J. A. et al. - Ach̆o da hldroxocobalamina na intoxlcacảo aguda do coelho pelo holocalix balanaa, Mlch. Rev. Fac. Med. vet. Zootec. Univ. S. Paulo, 8:159-64, 1972.

\section{T A B E L A I}

Ariministracan do extrato aquoso de Holocalix balanace. Mich. E de lldroxocobalamina por via enclovenosa em coclhos.

\begin{tabular}{|c|c|c|c|}
\hline \multirow{2}{*}{ 1. Administracáo } & \multicolumn{3}{|c|}{ Grupos de animais } \\
\hline & $\mathbf{A}$ & B & C \\
\hline Drogx & Extrato da planta & Extrato da planta & Ilidroxocobalamina \\
\hline Dose & $3,0 \quad \mathrm{~g} / \mathrm{Kg}$ & $3,0 \mathrm{~g} / \mathrm{Kg}$ & $10 \mathrm{mg} / \mathrm{Kg}$ \\
\hline Intervalo de tempo & \multirow{2}{*}{5 minutos } & \multirow{2}{*}{5 minutos } & \multirow{2}{*}{5 minutos } \\
\hline 2. administracăo & & & \\
\hline Droga & - & Hidroxocobalamina & Extrato da planta \\
\hline Dose & - & $10 \mathrm{mg} / \mathrm{Kg}$ & \\
\hline
\end{tabular}

T A B E L A I I

Resultado alcancado durante o perlodo de observacáo de 10 minutos em 15 coelhos, experimentalmente intoxicados em extrato aquoso de Holocalix balansae. Mich. (3,0 g/Kg) e relacionados com o năo tratamento, o tratamento posterior $c$ tratamento prévio a intoxicaça com hidroxocobalamina $(10 \mathrm{mg} / \mathrm{Kg})$. Os valores numéricos expressam a quantldade de animais.

\begin{tabular}{c|c|c|c}
\hline Grupo & $\begin{array}{c}\text { Alteracós na Prequencla } \\
\text { respiratórla }\end{array}$ & Mortalidade & Recuperacto \\
\hline A & 5 & 5 & 5 \\
B & $5 *$ & 0 & 5 \\
C & 0 & 0 & 5 \\
\hline
\end{tabular}

- Somente durante os 5 minutos que precederam a administracáo de HIdroxocobalamina.

tamina $\mathrm{B}_{12}$ à luz. Mais estável do que a cianocobalamina ou vitamina $B_{21 n}$, difere desta pela substituição do grupamento cianeto $(\mathrm{CN}-)$, ligado ao átomo central de cobalto, por um grupamento hidroxila ( $\mathrm{OH}-)$ o que confere-lhe uma certa basicidade. A hidroxocobalamina ê dotada de vários efeitos biológicos: antitóxicos (eliminaçāo do fon cianeto), hemopoiéticos, proteoanabólieos, hepatoprotetores e neurotrópicos.
DELGA 2 (1966), admite a capacidade da hidroxocobalamina interferir no metabolismo do ácido cianidrico, graças à sua propriedade de combinar-se com o fon cianeto, formando a cianocobalamina.

KILLANDER \& SCHILLING \& (1961), demonstraram que a hidroxocobalamina é eliminada lentamente pelos rins, após injeção única. A cianocobalamina desaparece da cir- 
SOUZA, J. A. et al. - Acăo da hidroxocobalamina na Intoxicacáo aguda do rociho pelo holocalix balansae, MIch. Rev. Fac. Mod. vet. Zootec. Univ. S. Paulo, 9:159-164, 8:159-64, 1972.

culaçāo após 24 horas de sua administração, enquanto que a hidroxocobalamina é elimidana por mais de 100 horas. Esta propriedade confere-lhe condiçăo terapéutica de cleiçāo no tratamento e profilaxía da intoxicaçăo cianídrica.

DFLGA et al. 3 (1961), colocam cm evidência a participaçăo da hidroxocobalamina na intoxicaçäo cianidrica experimental. Classicamente os antidotos preconizados para intoxicaçāo clanidrica podem ser classificados em três grupos: substancias possuidoras de grupamento carbonila; derivados sulfurados c alguns derivados metálicos. Nn primeirn grupo destas substâncias, situam-se os açúcares e a dioxicetona. A atividade antidota destas substáncias é atribuida à capacidade formadora de cianidrinas. Estas substancias desempenham ação preventiva antitóxica de importáncia, porém, ressentem-sr de qualquer açăo curativa. No scgundo grupo, incluem-se as substancias doadoras de enxofre, das quais podemos destacar: enxogre cololdal, hlposulfitos, tetrationatos, glutation reduzido, etc. Tem-se como certo que a atividade destas substáncias é devida a intervençăo da rodanase que transforma o cianeto $\mathrm{em}$ sulfucianctos, não $t o x i c o s$.

Finalmente, no terceiro grupo, destacam-se os derivados metálicos capazes de fixarem o Ion cianeto à metahemoglobina formada. Entre estas substáncias situa-se - azul de metileno, nitritos e para-aminopropiofenona.

Efeitos secundários desenvolvidos prlos agentes oxidantes da molécula hemoglobinica, têm sido referidos como incovenientes dritas substáncias.

Analisando-se os resultados alcançados por este experimento e, comparando-o aos trabalhos desenvolvidos por DELGA et al. 3 (1861) ? SCHEFFER et al. 10 (1970), podemos concluir ser a hidroxocobalamina a substáncia de escolha na profilaxia e tratamento da intoxicaçăo cianidrica pelo Holocalix balansac, Mich. e, certamente, por outras plantas cianogenéticas.

\section{RFMVA-1}

SouzA, J. A. - The action of Hidroxocobalamina in acute Holocalix balansae, Mich. poisoning in rabbits. Rov. Fac. Med. ver. Zootc. Univ. S. Paulo, 0:159-64, 1972.

SUMMARY - The authors poisoned expcrimentally 15 rabbits by an intravenous administration of an aqueous extract of Ifolocalix balansne, Mich.

The animals were distributed in 3 groups, each one composed by 5 animals. Group $A$ was considered as controll, and did not reccive any protection by hidroxocobalamin. Group $B$ received $10 \mathrm{mg} / \mathrm{Kg}$ of hidroxocobalamin intravenously, 5 minutes after as intravenous injection of an aqueous extract of Holocalix balansae, Mich. $(3,0 \mathrm{~g} / \mathrm{Kg})$. Finally, group $C$ received an intravenous dose of hidroxocobalamin $(10 \mathrm{mg} / \mathrm{Kg}) 5 \mathrm{mi}$ nutes before the intravenous administration of the aqueous extract of Holocalix balansae, Mich. $(\$, 0 \mathrm{~g} / \mathrm{Kg})$.

The vegetal extract was prepared accordingly with the procedure of SOUZA (1967). The presence of cyanide uras confirmed by the qualitative determination of FEIGL + (1954).

All animals of group $A$ died 10 minutes after the injection of the aqueous extract preceded by marked respiratory alferations. No death was observed among the animals of groups $B$ and C. Alterations of the respiratory frequancy were observed in the animals of group $B$, during the 5 minutes before the administration of hidroxocobnla. min. No alterations were observed in the animals of group $C$.

Finally, the authors concluded that the hidroxocobalamin is an ideal substance for the prophylaxis and treatment of cyanidrio poisoning by Holoaclix balansae, Mich. or any other cyanogenetic plant.

UNITERMS: Hidroxocobalamin *; Holocalix balansac *; Rabbits *; Poisoning*.

\section{REFERENCIAS BIBLIOGAFICAS}

1. BURKART, A. - Las leguminosas argentlans sllvestres y cultivadas. Buenos Alres, ACME Agency, 1952. p. 188. 
SOlZA, J. A. et al. - Açăo da hidroxocobátamina na intoxicaçăo aguda do coelho pelo holocalix balansae, Mich. Rev. Fac. Med. vet. Zootec. Univ. S. Paulo, B:159-164, 8:159-64, 1972.

2. DELGA, J. - Hydroxocobalamine et syndromes douloureux. Intérét des posologles massives. MEd. int. 10(1):5758, 1966.

3. DELGA, M. M. J. et al. - Recherrhe sur le traitement de l'intoxication cyanhydrique par l'hydroxocobalamine. Ann. pharm. Jranc. 19:740-52, 1961.

4. FEIGL, F. Spot test8. Amsterdam, Elsivier, 1954

5. FERNANDES, N. S. \& MACIUUZ, R. Toxldade da mescagnia pubillora Juss. Arq. Inst. Biol. (S. Paulo), 31: 1-4, 1964.

6. KILLANDER, A. \& SCIIILLING, R. F. Studies on hydroxocobalamin: excretion and retention of massive doses in control subjects. J. Lab. clin. Mćd., 57:553-61, 1961.

7. LUCAS, V. - o alecrim de Campinas. Rev. Flora med. (Rio de J.), 196: 70-9, 1941
8. MOREIRA, E. A. - Sobre a presenca de alcalóldes em Bacharis coridifolla. DC. Separaçåo por cromatografla em camada delgada. Trib. farm. (Curitiba), 26:5, 1966 .

9. Rocila E SILVA, M. - Fotossensibilizacăo $\mathrm{cm}$ bovinos. A peste das quelmadas, doenca causada pelo Holocalix glazlovill, Taub. Arq. Inst. Biol. (S. Paulo), 11:461-88, 1940.

10. SCHEFFER, J. G. et al, - Efeitos farmacológicos da hidroxocobalamina. Hospital (Rio de Janeiro), 78(2):3017, 1970.

11. SOUZA, J. A. - Propriedades farmacodinámicas e toxicológicas de extratos totais e de uma fracão quimicamente pura de holocalix balansae, Mich. Botucatu, 1967. [Tese - Faculdade de Cléncias Médicas e Biológicas de Botucatu].

Recebldo para publicacảo em 31-8-72

Aprovado para publicacăo em 19-10-72 